\title{
Ridding space of flotsam
}

\section{Washington}

AN exhibition of spacecraft and satellite parts damaged by orbiting debris, including a section of window from the space shuttle Challenger found to have been cratered by a chip of paint, was the centre-piece of a Congressional hearing last week.

The House of Representatives committee on Space Science and Application was learning about the hazards to spaceflight posed by the accumulated detritus of human activity in space. According to the National Aeronautics and Space Administration (NASA), a vehicle orbiting at $300 \mathrm{~km}$ altitude can expect to suffer a damaging collision once in 71 years, but if the density of debris increases at the present rate, that time will fall to 8 years in 2010 .

The Department of Defense has been tracking this space debris for some time, and estimates that there are now more than 7,000 objects bigger than $10 \mathrm{~cm}$ in low Earth orbit. But the greater danger is from smaller pieces, which are harder to detect and much more numerous. At velocities of up to $15 \mathrm{~km}$ per sec, microscopic fragments can cause fatal accidents.

Although low-flying debris gradually falls to Earth through atmospheric friction (a process quickened in the past few years as increased activity associated with the approaching solar maximum has puffed up the outer layers of the atmosphere) little can be done to clear away the mess.

The chairman of last week's subcommittee hearing, Representative Bill Nelson (Democrat, Florida), was concerned to find ways to slow the accumulation of debris, especially as more countries and independent organizations begin to launch commercial satellites.

The Federal Communications Commission (FCC) regulates satellite launching in the United States, but at present has no power to demand changes in design that would reduce 'littering'. Courtney Stadd of the Department of Transport speculated that FCC might be given greater control not only over the orbital placement of new satellites but also over their construction, even to the extent of disallowing painted signs on their surfaces.

Without international agreement, moves by the United States alone will not solve the problem, but Michael Michaud of the State Department's Office of Advanced Technology argued that US action against space debris would provide a base for international action. Although no immediate legislation is likely, there is a feeling that long-term questions of US space policy, neglected in the effort to get the shuttle relaunched, will soon demand answers.

David Lindley

\section{Endangered squirrel threatens Arizona observatory}

\section{Tucson}

To defend an endangered squirrel, the US Fish and Wildlife Service last Friday turned down a proposal by the University of Arizona (UA) to build seven telescopes on top of an 11,000-foot peak in southern Arizona. But a smaller observatory might be allowed.

For eight years, UA's Steward Observatory has eyed the peaks of Mount Graham for a major new observatory that would include the $11.3-\mathrm{m}$ binocular Columbus telescope and the 9-m submillimetre telescope funded in part by the Max Planck Institute. Peter A. Strittmatter, director of Steward Observatory, says the mountain-top location is desirable because it has good viewing conditions, is close to Tucson and has a road for easy access.

But Mount Graham is also a unique desert 'sky island', an outpost of old growth spruce-fir forest with a smattering of flora and fauna from Mexico, said Randall A. Smith, forest wildlife biologist with the Coronado National Forest. It has the densest population of black bear in the southwest and is the only home of the Mount Graham red squirrel, Tamias-

\section{A small step for SERC London}

Britain has taken a step forward in space research with the approval by the Science and Engineering Research Council (SERC) of participation in three new missions over the next eight years. The council has approved expenditure of $£ 16.3$ million on two missions which form the cornerstone of the European Space Agency's Horizon 2000 programme, dedicated to the study of solar terrestrial physics. These are the $\mathrm{SOHO}$ and Cluster missions. SOHO is due for launch in 1995 and will study the outer region of the Sun's atmosphere and the solar interior. Cluster, due to begin in late 1995 , will send four spacecraft into orbit round the Earth to study the evolution and properties of the plasma structure of the Earth's atmosphere.

SERC also approved involvement in a collaborative project with the Soviet Union. The Soviet Spectrum-X satellite, to be launched in 1992, will carry X-ray instruments for British spectroscopy experiments, with SERC spending £6 million on the mission. The third project approved involves participation in the Japanese Solar A mission. The satellite, due for launch in 1991, will host instruments for the study of high-energy phenomena in solar flares, concentrating on the impulsive phase when the prime energy release occurs. Christine McGourty ciurus hudsonicus grahamensis, classified as endangered in June 1987. That squirrel became the focus of a biological assessment by the U.S. Forest Service and of the Fish and Wildlife Service. Since 1984, UA has juggled telescope numbers, acreage and peaks to gain access to Mount Graham. Originally it asked for 40 to 60 acres for 13 telescopes spread over five sites, but in late 1986 asked for 10 telescopes on two peaks, High and Emerald Peaks. After assessing the biological impact, the US Forest Service suggested the observatory be limited to five telescopes on High Peak alone. UA responded that it had to have seven telescopes to make the observatory worthwhile.

According to the Fish \& Wildlife Service, those seven telescopes "will jeopardize the continued existence of this endangered species" and therefore would violate the Endangered Species Act.The opinion contained three "reasonable and prudent alternatives" that would allow some telescopes and still protect the squirrel. The opinion is a legally binding document that limits the options to those given in the opinion, said Smith. The university must decide by 22 July whether or not it wishes to pursue any of these alternatives.

One would be to build the telescopes elsewhere; the opinion notes that, of the telescopes specified by UA, only the Columbus Project needs be built in the continental United States and that there are two possible sites in New Mexico. But UA wants the observatory in its backyard, where new technology is being developed.

The other two options allow telescopes to be built on just one proposed site, but would close the mountain-top to the public and force out summer residents and a religious camp nearby. Expansion might be permitted in 10 years if no harm had come to the squirrel.

UA says a useful observatory on Mt Graham must have at least 7 telescopes. It could then also spread its estimated $\$ 11$ million annual operating costs between the various partners in the telescope projects. Another option allows the university to build an unspecified number of telescopes on 14 acres on High Peak. But in such a limited space, seven telescopes would change the local microclimate, negating the advantages of the site.

Once the university decides how to proceed, telescope construction may still be prevented by the Forest Service, which must not only protect the squirrel but also balance the needs of other Mount Graham users against the special interests of the astronomers.
Elizabeth Pennisi 